\title{
Consumption patterns of sweet drinks in a population of Australian children and adolescents (2003-2008)
}

Britt W Jensen ${ }^{1,2,3^{*}}$, Melanie Nichols ${ }^{4}$, Steven Allender ${ }^{4,5}$, Andrea de Silva-Sanigorski ${ }^{6}$, Lynne Millar ${ }^{4}$, Peter Kremer $^{7}$, Kathleen Lacy ${ }^{4}$ and Boyd Swinburn ${ }^{4}$

\begin{abstract}
Background: Intake of sweet drinks has previously been associated with the development of overweight and obesity among children and adolescents. The present study aimed to assess the consumption pattern of sweet drinks in a population of children and adolescents in Victoria, Australia.

Methods: Data on 1,604 children and adolescents (4-18 years) from the comparison groups of two quasiexperimental intervention studies from Victoria, Australia were analysed. Sweet drink consumption (soft drink and fruit juice/cordial) was assessed as one day's intake and typical intake over the last week or month at two time points between 2003 and 2008 (mean time between measurement: 2.2 years).

Results: Assessed using dietary recalls, more than $70 \%$ of the children and adolescents consumed sweet drinks, with no difference between age groups ( $p=0.28$ ). The median intake among consumers was $500 \mathrm{ml}$ and almost a third consumed more than $750 \mathrm{ml}$ per day. More children and adolescents consumed fruit juice/cordial (69\%) than soft drink (33\%) $(p<0.0001)$ and in larger volumes (median intake fruit juice/cordial: $500 \mathrm{ml}$ and soft drink: $375 \mathrm{ml}$ ). Secular changes in sweet drink consumption were observed with a lower proportion of children and adolescents consuming sweet drinks at time 2 compared to time 1 (significant for age group 8 to $<10$ years, $p=0.001$ ).

Conclusion: The proportion of Australian children and adolescents from the state of Victoria consuming sweet drinks has been stable or decreasing, although a high proportion of this sample consumed sweet drinks, especially fruit juice/cordial at both time points.
\end{abstract}

Keywords: Sweet beverages, Soft drink, Children and adolescents

\section{Background}

Overweight and obesity is one of the most significant health burdens for the Australian population, and in $200723 \%$ of children aged 2 to 16 years were assessed as overweight or obese [1-3]. High intake of sweet beverages may be one causal factor in the prevalence of obesity [4]. DiMeglio and Mattes [5] suggest that this may be caused by limited or no compensation in total energy intake after ingestion of liquid carbohydrates,

\footnotetext{
* Correspondence: britt.wang.jensen@regionh.dk

${ }^{1}$ Research Unit for Dietary Studies, Institute of Preventive Medicine, Copenhagen Capital Region, Copenhagen University Hospital, Frederiksberg, Denmark

${ }^{2}$ Centre for Research in Childhood Health, Institute of Sports Science and Clinical Biomechanics, University of Southern Denmark, Odense, Denmark Full list of author information is available at the end of the article
}

promoting an overall increased energy intake and positive energy balance. Soft drink and sugar-sweetened beverages have been associated with the development of overweight and obesity in childhood [6]. Several longitudinal studies [7-12] and a meta-analysis [13] have reported a direct association between intake of soft drink and other sweet drinks (a beverage category including fruit juice, fruit drink, cordial (a sweet, flavoured, concentrated syrup that is mixed with water to taste) and soft (carbonated) drinks) and weight gain in children and adolescents. Support for the association is not universal, however, with other longitudinal studies [14-17] and two meta-analyses $[18,19]$ not supporting the association.

In Australia, as in other countries, beverage consumption patterns are likely to have changed in recent times;

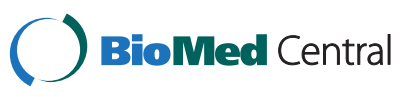


Table 1 Overview of similarities and differences in the two studies BAEW and IYM

\begin{tabular}{lll}
\hline & \multicolumn{1}{c}{ BAEW } & \multicolumn{1}{c}{ IYM } \\
\hline Area & Barwon-South Western Region of Victoria & Barwon-South Western Region of Victoria \\
\hline School level & Primary school & Secondary school \\
\hline Age & $4-12$ years & $12-18$ years \\
\hline Total $\mathbf{n}$ for study & $\begin{array}{l}2,184 \text { (845, from comparison group only, } \\
\text { included in analysis) }\end{array}$ & $\begin{array}{l}3,040 \text { (759, from comparison group only, } \\
\text { included in analysis) }\end{array}$ \\
\hline Year of data collection & Time 1: 2003/04, Time 2: 2006 & Time 1: 2005, Time 2: 2008 \\
\hline $\begin{array}{l}\text { Mean duration between } \\
\text { measurements }\end{array}$ & 2.1 years & 2.3 years \\
\hline Intervention in comparison & None & None \\
group & Soft drink and fruit juice/cordial & Soft drink and fruit drink/cordial \\
\hline Beverages assessed & Yesterday (always a week day) & Last school day \\
\hline Dietary recall & Last month & Last school week \\
\hline Frequency & The child's parent & The adolescent \\
\hline Respondent &
\end{tabular}

BAEW, Be Active Eat Well.

IYM, It's Your Move!

however we do not have a good understanding of the changes and their impact on child health outcomes. Further, little is known about how the patterns of sweet drink intake change in relation to demographics, gender and age. Recent Australian data on sweet drink consumption among children and adolescents are limited. A small number of state-based surveys $[2,3,20]$ and two recent Australian studies have been published examining the beverage intake among Australian children and adolescents [21,22], however, these were all cross-sectional, and were therefore not able to assess the longitudinal changes in the beverage consumption. This is an important gap in explaining obesity patterns among young people, and a better understanding is required to facilitate targeted planning for future interventions. The aim of the present study was therefore, among children and adolescents in the state of Victoria, Australia, to:

1. Examine consumption patterns of sweet drinks (sugar-sweetened soft drink and fruit juice/cordial), and the relative contribution of each beverage type.

2. Determine if patterns of sweet drink consumption change as children age and if this is associated with gender.

3. Examine the secular changes in the patterns of consumption of sweet drinks.

\section{Methods}

\section{Subjects}

The analyses for this paper bring together the comparison group data (excluding the intervention group) where no intervention was carried out. The data were collected as part of the evaluation of two obesity prevention interventions; Be Active Eat Well (BAEW) and It's Your Move! (IYM) (Table 1). The studies [23] were conducted in the Barwon-South Western Region of Victoria, Australia and included 5,224 children aged between 4 and 18 years. Data, including anthropometric measurements and dietary intake data, were collected at two time points between 2003 and 2008. The two studies are described briefly below and in more detail elsewhere $[23,24]$.

This study was conducted according to the guidelines laid down in the Declaration of Helsinki and all procedures involving human subjects were approved by Deakin University Human Research Ethics Committee (IYM: EC37-2004, BAEW: EC20-2003). Written informed consent was obtained from all participants and/or the parents of participants aged less than 18 years. In addition, verbal assent was obtained from all children and adolescents on the day of data collection.

\section{Be Active Eat Well (BAEW)}

The evaluation of BAEW included 2,184 primary school children aged 4 to 12 years and their families. The intervention was conducted in the township of Colac, with a stratified random sample of the remainder of the Barwon-South Western Region of Victoria providing the comparison group $(n=1,183,44 \%$ of the invited population) (Table 1) [24]. Baseline data were collected in 2003/04 (time 1) and post-intervention data in early/mid 2006 (time 2, mean duration between the measurements was 2.1 years) and included a computer assisted telephone interview (CATI) survey of the children's parents with questions concerning the child's food and beverage intake, physical activity and family socio-demographic characteristics $[24,25]$. From BAEW, 39 children aged between 12 and 13 years were excluded from this analysis to ensure that the age groups in the two studies did not overlap. 


\section{It's Your Move! (IYM)}

IYM was one of four sites in the Pacific Obesity Prevention in Communities (OPIC) project [26] and included 3,040 adolescents aged between 12 and 18 years. The intervention was conducted in secondary schools in the East Geelong and Bellarine Peninsula regions of Victoria with a stratified random sample of schools from the Barwon-South Western Region of Victoria serving as the comparison group ( $\mathrm{n}=1,188,47 \%$ of the invited population) (Table 1) [26]. The data were collected in winter/ spring at two time points between 2005 and 2008 with a mean duration between measurements of 2.3 years. Data collection included an 83-question Adolescent Behaviours, Attitude and Knowledge Questionnaire completed by the adolescents [27]. This questionnaire was developed and used across the four sites of the OPIC study and included information on key behaviours such as dietary practices, physical activity and perceptions of school, home and neighbourhood environments.

Across the combined studies only children from the comparison groups with complete information on beverage intake at both time points were included in the analysis, resulting in 1,604 participants (845 from BAEW and 759 from IYM, 31\% and $30 \%$ of the invited populations, respectively).

\section{Dietary assessment}

One day's intake of soft drink and fruit juice/cordial was assessed (along with other selected foods) using two questions at both time points as parent-report (BAEW) or self-report by the adolescent (IYM). In addition, intake of soft drink and fruit juice/cordial was reported per month (BAEW) or per week (IYM).

In BAEW the questions used to assess intake of soft drink and fruit juice/cordial at time 1 were:

\section{"How many cans of soft drink did the child drink yesterday? [By cans, we mean the $375 \mathrm{mls}$ cans that you would see in supermarkets or convenience stores. Diet soft drinks are NOT included.]" and "How many serves of fruit juice or cordial did the child drink yesterday? [By serves we mean the small $250 \mathrm{ml}$ tetra paks or a standard glass. The types of drinks include $100 \%$ fruit juices, diluted fruit juice drinks, and cordials]".}

At time 2 the question assessing the intake of soft drink was slightly changed and referred to $250 \mathrm{ml}$ glasses instead of $375 \mathrm{ml}$ cans, while the question for intake of fruit juice/cordial remained unchanged. Furthermore, intake of soft drink and fruit juice/cordial was assessed as frequency per month in BAEW, with seven categorical ordinal response options ranging from less than once a month to two or more times per day. At both time 1 and 2 the intake of the participants in BAEW was assessed by the children's parents.

In IYM the beverage intake was assessed in the Adolescent Behaviours, Attitude and Knowledge Questionnaire using the questions;

"On the last school day, how many glasses or cans of non-diet soft drinks did you have?" and, "On the last school day, how many glasses of fruit drinks or cordial did you have?".

In IYM one glass/can of soft drink was assumed to equal 150/300 $\mathrm{ml}$ and one glass of fruit juice/cordial was assumed to equal $250 \mathrm{ml}$. In addition the frequency of soft drink and fruit juice/cordial intake during the last school week was assessed in IYM with possible responses ranging from none to five days.

The number of glasses/cans reported was converted to millilitres to enable comparison between the studies. The reported intakes of soft drink and fruit juice/cordial yesterday or last school day were used to derive total 'sweet drinks'. 'Diet' and artificially sweetened beverages were not included in the assessment of any of the beverage categories.

\section{Socioeconomic status}

Socioeconomic status (SES) was determined using the 2001 Socioeconomic Index for Areas (SEIFA) area level scores [28] based on the participant's area of residence. The scores are based on a summary of several measures representing different aspects of relative socioeconomic advantage and disadvantage in a geographic area $[23,24,28]$. In this study, SEIFA values were dichotomised, dividing the areas into high/low SES based on the state wide median.

\section{Anthropometric measurements}

Weight and height were measured at both time points in light clothing and without shoes by trained researchers according to standard methods for collecting anthropometric data in children [29].

Body mass index (BMI) was calculated from measured height and weight as $\mathrm{kg} / \mathrm{m}^{2}$ and age- and gender- standardized BMI z-scores were calculated according to the WHO Child Growth Standard for children $<5$ years [30] and the Child Growth Reference for children $>5$ years [31]. Dichotomous weight status (healthy weight or overweight/obese) was defined according to the cut-points recommended by WHO. Due to the limited number of participants $<5$ years $(n=60)$ the cut point for children $>5$ years (overweight including obesity defined as a BMI z-score of $>1$ [32]) was used for all subjects including children $<5$ years in the present study. 


\section{Statistical analysis}

Descriptive statistics were calculated by age group and gender, and differences between these were tested by Chi-squared test for categorical data and ANOVA for continuous data. Spearman's rank correlation coefficient was used to assess the correlation between yesterday's intake (or last school day for IYM) and the intake last month (BAEW) or last school week (IYM) for soft drink and fruit juice/cordial for each study.

Beverage intake was reported as percentage of children who consumed the beverage on the previous day (BAEW) or previous school day (IYM) and percentage of children consuming $\leq 375 \mathrm{ml}$ (one can), 376-749 $\mathrm{ml}$ (one to two cans) or $\geq 750 \mathrm{ml}$ (more than two cans), respectively. Data are presented for all participants, by age group and gender, and as change in intake from time 1 to time 2. Differences between participants reporting increased, decreased or no change in intake from time 1 to time 2 were tested by Chi-squared test for categorical data and ANOVA for continuous data.

Difference in the proportion of consumers between time 1 and time 2 was tested by McNemar's test for paired data in the longitudinal analysis. Secular changes in proportion of consumers, differences between gender and differences in proportion of consumers between age groups were tested by Chi-squared test. Secular changes in the proportion of participants consuming sweet drinks were assessed by comparing participants in each age group at time 1 with the participants who were at similar age at time 2. E.g. children aged 6 to $<8$ years in 2003/04 (time 1) were compared with those aged 6 to $<8$ years in 2006 (time 2, 4 to $<6$ years at time 1 ). A few participants only did not change age group from time 1 to time 2 and these were excluded from the analyses to ensure that the groups compared were independent.

Analyses were conducted using Stata version 11 (StataCorp LP, Texas, USA), and results were considered significant at $\mathrm{p}<0.05$. Bonferroni correction was used to take into account the multiple comparisons.

\section{Results}

\section{Participants}

Data on 1,604 children and adolescents were analysed for the current study. There were slightly fewer males than females in the sample $(47.8 \%$, no significant differences across age groups (NS)) and the mean age was 11.2 years (SD 3.7 years) (Table 2). BMI increased as expected with age $(\mathrm{p}<0.0001)$ and overall the females had higher BMI than the males $(\mathrm{p}=0.002)$. BMI z-score and weight status also differed by age $(\mathrm{p}<0.0001$ for both) but no significant difference was observed between genders (data not shown). The children and adolescents

Table 2 Descriptive characteristics of participants at time 1

\begin{tabular}{|c|c|c|c|c|c|c|c|c|c|}
\hline & \multirow[b]{3}{*}{ All } & \multicolumn{7}{|c|}{ Age at time 1} & \multirow[b]{3}{*}{$\mathrm{p} \ddagger$} \\
\hline & & \multicolumn{4}{|c|}{ BAEW } & \multicolumn{3}{|c|}{ IYM } & \\
\hline & & $\begin{array}{c}4 \text { to }<6 \\
\text { years }\end{array}$ & $\begin{array}{c}6 \text { to }<8 \\
\text { years }\end{array}$ & $\begin{array}{c}8 \text { to }<10 \\
\text { years }\end{array}$ & $\begin{array}{c}10 \text { to }<12 \\
\text { years }\end{array}$ & $\begin{array}{c}12 \text { to }<14 \\
\text { years }\end{array}$ & $\begin{array}{c}14 \text { to }<16 \\
\text { years }\end{array}$ & $\begin{array}{c}16 \text { to }<18 \\
\text { years }\end{array}$ & \\
\hline \multirow{2}{*}{$\begin{array}{l}\text { Distribution } \\
\text { n (\%) }\end{array}$} & 1604 & 169 & 214 & 278 & 184 & 309 & 277 & 173 & \\
\hline & $(100.0)$ & $(10.3)$ & $(14.0)$ & $(18.3)$ & $(12.1)$ & $(20.0)$ & (17.9) & $(11.2)$ & \\
\hline \multirow{2}{*}{$\begin{array}{l}\text { Gender (males) } \\
\text { n (\%) }\end{array}$} & 766 & 87 & 97 & 144 & 87 & 152 & 132 & 67 & 0.16 \\
\hline & $(47.8)$ & $(51.5)$ & $(45.3)$ & $(51.8)$ & $(47.3)$ & $(49.2)$ & $(47.7)$ & $(38.7)$ & \\
\hline \multirow[t]{2}{*}{ BMI } & 19.6 & 16.7 & 16.8 & 18.2 & 19.2 & 21.0 & 21.6 & 22.7 & $<0.00001$ \\
\hline & (3.6) & $(1.8)$ & $(2.1)$ & $(2.8)$ & $(3.0)$ & (3.8) & $(3.2)$ & $(3.3)$ & \\
\hline \multirow{2}{*}{$\begin{array}{l}\text { BMI z-score } \\
\text { mean (SD)* }\end{array}$} & 0.6 & 0.9 & 0.6 & 0.9 & 0.7 & 0.6 & 0.4 & 0.4 & $<0.00001$ \\
\hline & $(1.0)$ & $(1.0)$ & $(1.0)$ & $(1.0)$ & $(1.0)$ & $(1.1)$ & $(0.9)$ & (0.9) & \\
\hline \multirow{2}{*}{$\begin{array}{l}\text { SES (below state } \\
\text { wide median) } \\
\mathrm{n}(\%) \S\end{array}$} & 967 & 83 & 142 & 169 & 119 & 198 & 161 & 95 & 0.008 \\
\hline & $(61.4)$ & $(49.4)$ & $(67.0)$ & $(61.2)$ & $(64.7)$ & (65.6) & $(60.1)$ & (57.6) & \\
\hline \multirow{2}{*}{$\begin{array}{l}\text { Overweight/ obese } \\
\text { n (\%)* }\end{array}$} & 529 & 67 & 69 & 115 & 70 & 102 & 62 & 44 & $<0.0001$ \\
\hline & $(33.3)$ & $(39.6)$ & (32.4) & $(41.4)$ & $(38.0)$ & (33.6) & $(22.8)$ & $(25.7)$ & \\
\hline
\end{tabular}

P-value for the difference between age groups.

*Due to missing data on weight and/or height, $n$ is different for following groups; total $n=1591,6$ to $<8$ years $n=213,12$ to $<14$ years $n=304,14$ to $<16$ years $\mathrm{n}=272,16$ to $<18$ years $\mathrm{n}=171$.

§ Due to missing data on SES, $n$ is different for following groups; total $n=1575,4$ to $<6$ years $n=168,6$ to $<8$ years $n=212,8$ to $<10$ years $n=27612$ to $<14$ years $n=302,14$ to $<16$ years $n=268,16$ to $<18$ years $n=165$.

BAEW, Be Active Eat Well.

IYM, It's Your Move!

BMI, body mass index.

BMI z-score, body mass index z-scores.

SES, socio-economic status.

Overview of distribution of age groups and descriptive characteristics of participants at time 1 . 
Table 3 Longitudinal changes in proportion of beverage consumers

\begin{tabular}{|c|c|c|c|c|c|c|c|}
\hline & \multirow[b]{3}{*}{ Age at time 1} & \multirow[b]{3}{*}{ Total $\mathbf{n}$} & \multirow{2}{*}{\multicolumn{2}{|c|}{$\begin{array}{c}\text { Time } 1 \\
\text { Consumers }\end{array}$}} & \multirow{2}{*}{\multicolumn{2}{|c|}{$\begin{array}{c}\text { Time } 2 \\
\text { Consumers }\end{array}$}} & \multirow[t]{3}{*}{$\mathrm{p} \ddagger$} \\
\hline & & & & & & & \\
\hline & & & $\mathrm{n}$ & (\%) & $\mathrm{n}$ & (\%) & \\
\hline \multirow[t]{9}{*}{ Sweet drinks (total) } & All & 1604 & 1232 & $(76.8)$ & 1145 & $(71.4)$ & $<0.00001$ \\
\hline & 4 to $<6$ years & 169 & 125 & $(74.0)$ & 112 & $(66.3)$ & 0.06 \\
\hline & 6 to $<8$ years & 214 & 157 & $(73.4)$ & 140 & $(65.4)$ & 0.04 \\
\hline & 8 to $<10$ years & 278 & 221 & (79.5) & 215 & $(77.3)$ & 0.53 \\
\hline & 10 to $<12$ years & 184 & 146 & $(79.4)$ & 141 & $(76.6)$ & 0.54 \\
\hline & 12 to $<14$ years & 309 & 248 & $(80.3)$ & 233 & $(75.4)$ & 0.12 \\
\hline & 14 to $<16$ years & 277 & 206 & $(74.4)$ & 188 & (67.9) & 0.06 \\
\hline & 16 to $<18$ years & 173 & 129 & $(74.6)$ & 116 & $(67.1)$ & 0.09 \\
\hline & $p \S$ & & & 0.28 & & 0.004 & \\
\hline \multirow[t]{9}{*}{ Fruit juice/cordial } & All & 1604 & 1106 & $(69.0)$ & 1017 & $(63.4)$ & 0.0001 \\
\hline & 4 to $<6$ years & 169 & 111 & $(65.7)$ & 102 & $(60.4)$ & 0.26 \\
\hline & 6 to $<8$ years & 214 & 145 & $(67.8)$ & 123 & $(57.5)$ & 0.02 \\
\hline & 8 to $<10$ years & 278 & 199 & (71.6) & 192 & $(69.1)$ & 0.49 \\
\hline & 10 to $<12$ years & 184 & 129 & $(70.1)$ & 127 & $(69.0)$ & 0.89 \\
\hline & 12 to $<14$ years & 309 & 222 & (71.8) & 201 & $(65.1)$ & 0.05 \\
\hline & 14 to $<16$ years & 277 & 183 & $(66.1)$ & 167 & $(60.3)$ & 0.11 \\
\hline & 16 to $<18$ years & 173 & 117 & $(67.6)$ & 105 & $(60.7)$ & 0.13 \\
\hline & $p \S$ & & & 0.62 & & 0.06 & \\
\hline \multirow[t]{9}{*}{ Soft drink } & All & 1604 & 532 & (33.2) & 442 & (27.6) & 0.0001 \\
\hline & 4 to $<6$ years & 169 & 36 & $(21.3)$ & 23 & $(13.6)$ & 0.04 \\
\hline & 6 to $<8$ years & 214 & 42 & (19.6) & 47 & $(22.0)$ & 0.59 \\
\hline & 8 to $<10$ years & 278 & 80 & (28.8) & 69 & $(24.8)$ & 0.27 \\
\hline & 10 to $<12$ years & 184 & 52 & (28.3) & 48 & $(26.1)$ & 0.70 \\
\hline & 12 to $<14$ years & 309 & 153 & $(49.5)$ & 124 & $(40.1)$ & 0.009 \\
\hline & 14 to $<16$ years & 277 & 102 & $(36.8)$ & 77 & $(27.8)$ & 0.09 \\
\hline & 16 to $<18$ years & 173 & 67 & $(38.7)$ & 54 & $(31.2)$ & 0.12 \\
\hline & $p \S$ & & & $<0.0001$ & & $<0.0001$ & \\
\hline
\end{tabular}

+ P-value for the difference between the proportion of consumers between time 1 and time 2, tested by McNemar's test.

$\S$ P-value for the difference in the proportion of consumers between age groups, tested by Chi-squared test.

Intake of sweet drinks, fruit juice/cordial and soft drinks (yesterday or last school day) by baseline age groups at time 1 and time 2 presented as percentage consumers.

included in the study were generally from families residing in lower SES areas compared to the state wide median.

The correlation between one day's intake and intake last week/ month ranged from 0.48 to 0.58 for soft drink ( $\mathrm{p}<0.00001$ ) and 0.734 to 0.78 for fruit juice/cordial ( $\mathrm{p}$ $<0.00001$ ) differing by time point (time 1/time 2) and study (BAEW/IYM).

\section{Intake of sweet drinks}

Overall $77 \%$ of the participants reported consuming any type of sweet drink (soft drink or fruit juice/cordial) yesterday or on the last school day (Table 3). The median intake of sweet drinks among consumers was $500 \mathrm{ml}$ (data not shown), and almost a third (31\%) of all children and adolescents consumed more than $750 \mathrm{ml}$ (two cans or three glasses) (Table 4).
When the different types of sweet drinks were analysed separately, fruit juice/cordial was consumed by $69 \%$ of the children and adolescents (Table 3) with a median intake of $500 \mathrm{ml}$ per day while $33 \%$ reported consuming soft drink (median intake $375 \mathrm{ml}$ ) (data not shown). More than one in five participants (21\%) reported consuming more than $750 \mathrm{ml}$ of fruit juice/cordial (Table 4). Among those who reported consuming soft drinks on the previous day, almost three quarters (71\%) consumed the equivalent of one can of soft drink or less.

There were no significant differences in the proportion of participants consuming sweet drinks between the age groups at time 1 for all sweet drinks combined ( $\mathrm{p}=$ $0.28)$ or fruit juice/cordial specifically $(\mathrm{p}=0.62)$ (Table 3$)$. However, significant differences between the age groups 
Table 4 Longitudinal changes in beverage consumption

\begin{tabular}{|c|c|c|c|c|c|c|c|c|c|}
\hline & \multicolumn{5}{|c|}{ Time 1} & \multicolumn{4}{|c|}{ Time 2} \\
\hline & & None & $\leq 375 \mathrm{ml}$ & $376-749 \mathrm{ml}$ & $\geq 750 \mathrm{ml}$ & None & $\leq 375 \mathrm{ml}$ & $376-749 \mathrm{ml}$ & $\geq 750 \mathrm{ml}$ \\
\hline \multicolumn{10}{|c|}{ Sweet drinks (total) } \\
\hline \multirow[t]{2}{*}{ All } & $\mathrm{n}$ & 372 & 397 & 341 & 494 & 459 & 439 & 317 & 389 \\
\hline & (\%) & $(23.2)$ & $(24.8)$ & $(21.3)$ & $(30.8)$ & $(28.6)$ & $(27.4)$ & $(19.8)$ & $\frac{(24.3)}{2}$ \\
\hline \multirow[t]{2}{*}{ Males } & $\mathrm{n}$ & 154 & 174 & 173 & 265 & 195 & 192 & 151 & 228 \\
\hline & (\%) & $(20.1)$ & (22.7) & $(22.6)$ & $(34.6)$ & $(25.5)$ & $(25.1)$ & $(19.7)$ & $(29.8)$ \\
\hline \multirow[t]{2}{*}{ Females } & $\mathrm{n}$ & 218 & 223 & 168 & 229 & 264 & 247 & 166 & 161 \\
\hline & $(\%)$ & $(26.0)$ & (26.6) & $(20.1)$ & $(27.3)$ & $(31.5)$ & $(29.5)$ & (19.8) & $(19.2)$ \\
\hline \multicolumn{2}{|c|}{$p \S$} & & & 0.001 & & & & $<0.0001$ & \\
\hline \multicolumn{10}{|c|}{ Fruit juice/cordial } \\
\hline \multirow[t]{2}{*}{ All } & $\mathrm{n}$ & 498 & 441 & 323 & 342 & 587 & 477 & 268 & 272 \\
\hline & (\%) & $(31.1)$ & $(27.5)$ & $(20.1)$ & $(21.3)$ & $(36.6)$ & $(29.7)$ & $(16.7)$ & $(17.0)$ \\
\hline \multirow[t]{2}{*}{ Males } & $n$ & 216 & 206 & 166 & 178 & 258 & 219 & 140 & 149 \\
\hline & (\%) & $(28.2)$ & (26.9) & $(21.7)$ & $(23.2)$ & $(33.7)$ & $(28.6)$ & (18.3) & (19.5) \\
\hline \multirow[t]{2}{*}{ Females } & $n$ & 282 & 235 & 157 & 164 & 329 & 258 & 128 & 123 \\
\hline & (\%) & $(33.7)$ & $(28.0)$ & $(18.7)$ & (19.6) & $(39.3)$ & $(30.8)$ & $(15.3)$ & $(14.7)$ \\
\hline$p \S$ & & & & 0.04 & & & & 0.009 & \\
\hline \multicolumn{10}{|l|}{ Soft drink } \\
\hline \multirow[t]{2}{*}{ All } & $\mathrm{n}$ & 1072 & 380 & 60 & 92 & 1162 & 306 & 96 & 40 \\
\hline & (\%) & $(66.8)$ & (23.7) & (3.7) & (5.7) & $(72.4)$ & $(19.1)$ & (6.0) & (2.5) \\
\hline \multirow[t]{2}{*}{ Males } & $n$ & 492 & 179 & 37 & 58 & 507 & 169 & 61 & 29 \\
\hline & (\%) & $(64.2)$ & (23.4) & (4.8) & (7.6) & $(66.2)$ & (22.1) & (8.0) & (3.8) \\
\hline \multirow[t]{2}{*}{ Females } & $n$ & 580 & 201 & 23 & 34 & 655 & 137 & 35 & 11 \\
\hline & (\%) & $(69.2)$ & $(24.0)$ & (2.7) & (4.1) & $(78.2)$ & $(16.4)$ & $(4.2)$ & (1.3) \\
\hline$p \S$ & & & & 0.002 & & & & $<0.0001$ & \\
\hline
\end{tabular}

$\S$ P-value for the difference in the distribution of consumer between genders, tested by Chi-squared test.

Intake of sweet drinks, fruit juice/cordial and soft drink by gender. Presented as proportion of consumers yesterday or last school day in four categories.

were found in the proportion of children and adolescents who reported consuming soft drink $(\mathrm{p}<0.0001)$, with more consumers among the adolescents in secondary school compared to the children in primary school.

Significantly more males than females consumed any sweet drinks overall $(\mathrm{p}=0.005)$ at time 1 and among older adolescents (age group 14 to $<16$ years $\mathrm{p}=0.003$, age group 16 to $<18$ years $\mathrm{p}=0.01$ ) (data not shown).

\section{Longitudinal changes over time}

The longitudinal data showed that at time 1, 77\% of the participants consumed any sweet drinks, while at time 2, the proportion was $71 \%$ ( $\mathrm{p}<0.00001$ ) (Table 3). The prevalence of fruit juice/cordial consumption reduced from $69 \%$ at time 1 to $63 \%$ at time $2(\mathrm{p}=0.0001)$ and soft drink consumption prevalence was $33 \%$ at time 1 and $28 \%$ at time $2(\mathrm{p}=0.0001)$. This trend toward a decreasing proportion of consumers was observed in most age groups, but was only statistically significant in a few cases. After adjusting for multiple comparisons only the tests including all children and adolescents remained significant.
Almost half of the children in BAEW (44\%) and just over one third of the adolescents in IYM (37\%) reported constant intake of sweet drinks and another one third in both groups (BAEW: 33\%, IYM: 38\%) reported decreased intake from time 1 to time 2 while the remaining one quarter (BAEW: 23\%, IYM: 25\%) reported increased intake (Table 5). The consumption of fruit juice/cordial followed a similar pattern to overall consumption but the pattern of soft drink consumption differed. Compared to levels of consumption of fruit juice/ cordial over time, a larger proportion of children and adolescents reported constant intake of soft drink and the majority of those were in the group that reported no consumption at both time points. A smaller proportion of children reported a change in levels of intake of soft drink.

The proportion of adolescents who reported increased, decreased or no change in intake of soft drink from time 1 to time 2 differed in gender $(\mathrm{p}<0.001)$ and SES ( $\mathrm{p}=$ $0.01)$. More males (23\%) than females (10\%) reported increased intake of sweet drinks, while more females (64\%) than males (49\%) reported no change in intake 
Table 5 Persistence of beverage consumption patterns

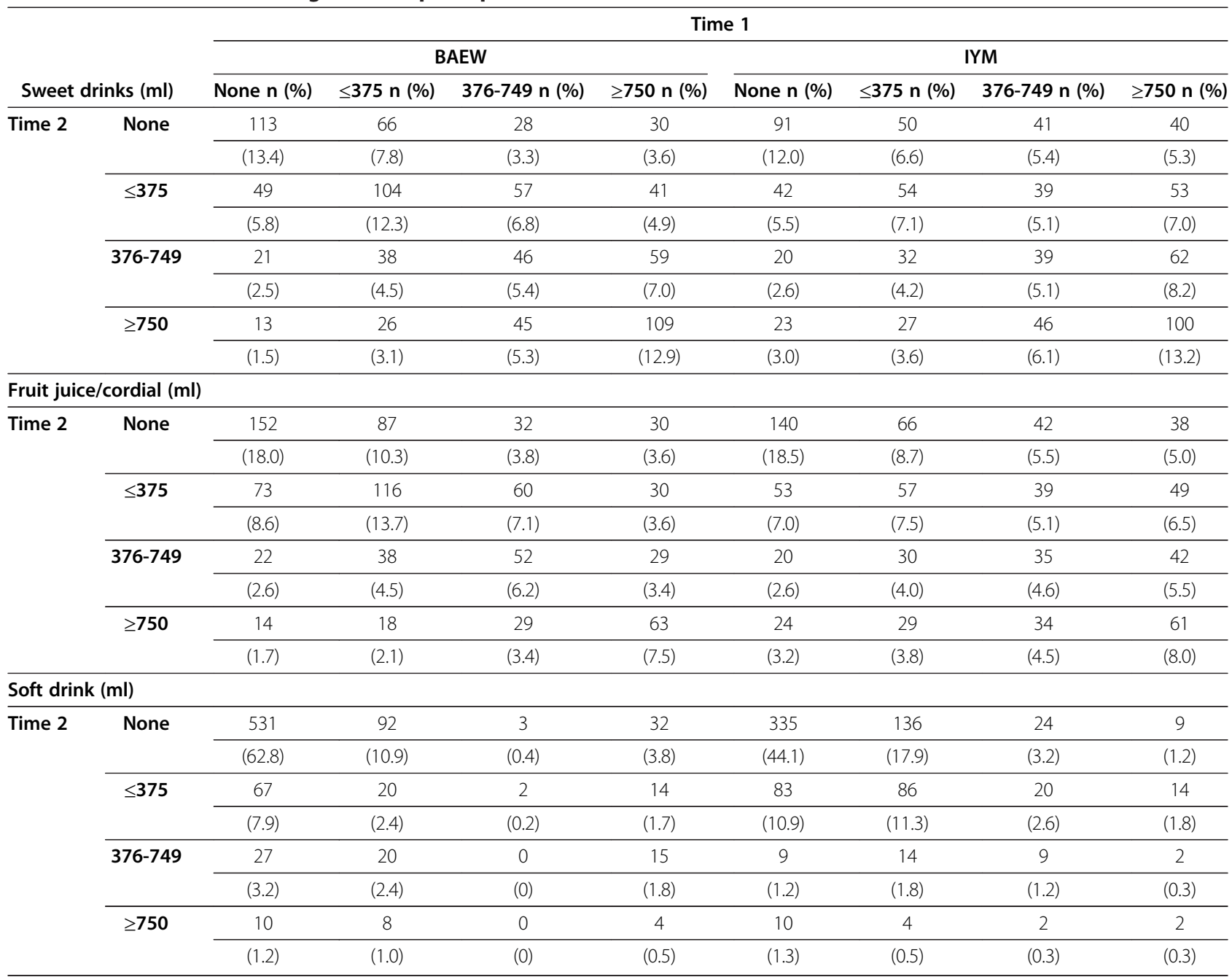

BAEW, Be Active Eat Well.

IYM, It's Your Move!

The proportion of participants reporting increased, decreased or no change in intake of sweet drinks, fruit juice/cordial and soft drink from time 1 to time 2 ,

based on the reported intake yesterday or last school day and presented by study.

(data not shown). Also, more adolescents from families residing in low SES areas reported increased intake (low SES: 19\%, high SES: 12\%) while more adolescents from families residing in high SES areas reported decreased intake (low SES: 24\%, high SES: 31\%) from time 1 to time 2 and a similar trend was observed for sweet drink $(\mathrm{p}=0.05)$ (data not shown). The proportion of children who reported increased, decreased or no change in intake of soft drink differed in SES $(p<0.001)$. More children from families residing in low SES areas reported decreased intake (low SES: 23\%, high SES: 12\%) while more children residing in high SES areas reported no change intake of soft drink (low SES: 60\%, high SES: 73\%) (data not shown). Furthermore, children who reported increased, decreased or no change in intake of sweet drinks and fruit juice/cordial differed in age (sweet drinks $\mathrm{p}=0.004$, fruit juice/cordial $\mathrm{p}=0.02$ ) with a trend toward that children who decreased their intake were younger, while those who increased their intake were older.

\section{Cross-sectional changes over time}

The secular changes in sweet drink consumption were assessed using a serial cross-sectional analysis of the data in which the same age groups were compared at time 1 (BAEW: 2003/04, IYM: 2005) and time 2 (BAEW: 2006, IYM: 2008) (Table 6). A non-significant trend toward lower proportions of children and adolescents consuming any sweet drink at time 2 compared to time 1 was observed most age groups (Table 6). A significant difference was observed for age group 8 to $<10$ years where $80 \%$ of the children reported consuming sweet drinks at 
Table 6 Secular changes in proportion of beverage consumers

\begin{tabular}{|c|c|c|c|c|c|c|c|c|}
\hline \multirow[t]{3}{*}{ BAEW } & \multicolumn{4}{|c|}{ Time $1(2003 / 4)$} & \multicolumn{3}{|c|}{ Time 2 (2006) } & \multirow[t]{3}{*}{$p \S$} \\
\hline & \multirow[b]{2}{*}{ Age } & \multicolumn{2}{|c|}{ Consumers } & \multirow[b]{2}{*}{ Total $\mathbf{n}$} & \multicolumn{2}{|c|}{ Consumers } & \multirow[b]{2}{*}{ Total $n$} & \\
\hline & & $\mathrm{n}$ & $(\%)$ & & $\mathrm{n}$ & (\%) & & \\
\hline \multirow[t]{3}{*}{ Sweet drinks (total) } & 6 to $<8$ years & 150 & $(73.9)$ & 203 & 112 & $(66.3)$ & 169 & 0.11 \\
\hline & 8 to $<10$ years & 218 & $(80.1)$ & 272 & 134 & $(66.0)$ & 203 & 0.001 \\
\hline & 10 to $<12$ years & 142 & $(79.9)$ & 180 & 211 & $(77.6)$ & 272 & 0.74 \\
\hline \multirow[t]{3}{*}{ Fruit juice/cordial } & 6 to $<8$ years & 138 & $(68.0)$ & 203 & 102 & $(60.4)$ & 169 & 0.13 \\
\hline & 8 to $<10$ years & 196 & $(72.1)$ & 272 & 117 & (57.6) & 203 & 0.001 \\
\hline & 10 to $<12$ years & 125 & $(69.4)$ & 180 & 188 & $(69.1)$ & 272 & 0.94 \\
\hline \multirow[t]{3}{*}{ Soft drink } & 6 to $<8$ years & 42 & $(20.7)$ & 203 & 23 & $(13.6)$ & 169 & 0.73 \\
\hline & 8 to $<10$ years & 79 & $(29.0)$ & 272 & 45 & $(22.2)$ & 203 & 0.09 \\
\hline & 10 to $<12$ years & 51 & $(28.3)$ & 180 & 69 & $(25.4)$ & 272 & 0.49 \\
\hline \multirow[t]{3}{*}{ IYM } & \multicolumn{4}{|c|}{ Time 1 (2005) } & & \multicolumn{2}{|c|}{ Time 2 (2008) } & $\mathbf{p} \S$ \\
\hline & & \multicolumn{2}{|c|}{ Consumers } & & \multicolumn{2}{|c|}{ Consumers } & & \\
\hline & Age & $\mathrm{n}$ & (\%) & Total $n$ & $\mathrm{n}$ & $(\%)$ & Total $\mathbf{n}$ & \\
\hline \multirow[t]{2}{*}{ Sweet drinks (total) } & 14 to $<16$ years & 206 & $(74.4)$ & 277 & 233 & $(75.4)$ & 309 & 0.77 \\
\hline & 16 to $<18$ years & 75 & $(77.3)$ & 97 & 188 & $(67.9)$ & 277 & 0.08 \\
\hline \multirow[t]{2}{*}{ Fruit juice/cordial } & 14 to $<16$ years & 183 & $(66.1)$ & 277 & 201 & $(65.1)$ & 309 & 0.80 \\
\hline & 16 to $<18$ years & 68 & $(70.1)$ & 97 & 167 & $(60.3)$ & 277 & 0.09 \\
\hline \multirow[t]{2}{*}{ Soft drink } & 14 to $<16$ years & 102 & $(36.8)$ & 277 & 124 & $(40.1)$ & 309 & 0.41 \\
\hline & 16 to $<18$ years & 43 & $(44.3)$ & 97 & 77 & $(27.8)$ & 277 & 0.003 \\
\hline
\end{tabular}

\#Children and adolescents who remained in the same age group at both time points were excluded from these analyses.

§-value for the difference between the proportion of consumers at time 1 compared to time 2, tested by Chi-squared test.

Intake of sweet drinks, soft drink and fruit juice/cordial by age and cohort, presented as percentage consumers yesterday or last school day.

time 1 and $66 \%$ in the same age group at time 2 ( $\mathrm{p}=$ 0.001). Overall a decreasing proportion of children and adolescents reported consuming any type of sweet drinks at time 2 compared to time 1.

When the two types of sweet drinks were analysed separately, the proportion of children and adolescents consuming fruit juice/cordial and soft drinks appeared to decrease from time 1 to time 2 , however the difference was only significant in age group 8 to $<10$ years for fruit juice/cordial $(\mathrm{p}=0.001)$ and 16 to $<18$ years for soft drink ( $\mathrm{p}=0.003$ ) (Table 6). Adjusting for multiple comparisons the results remained significant.

\section{Discussion}

This study examined the pattern of intake of sweet drinks, including nutritively sweetened soft drinks and fruit juice/cordial, among children and adolescents from Victoria, Australia. According to the dietary recalls more than $70 \%$ of the children and adolescents consumed sweet drinks and of these consumers, $40 \%$ had the equivalent of more than two cans $(\geq 750 \mathrm{ml})$ of sweet drinks. Significantly more participants consumed fruit juice/cordial compared to soft drinks. The proportion of participants who reported consuming sweet drinks overall, and fruit juice/cordial specifically, varied with gender but remained stable across age groups, however there was a greater proportion of soft drink consumers in the older age groups. The proportion of children and adolescents consuming sweet drinks remained relatively stable over time, with some significant decreases in consumption, both longitudinally within cohorts, and in repeated cross-sections of comparable age groups.

\section{Intake of sweet drinks}

The majority of existing research on sweet drink consumption has focused specifically on soft drinks. This study found that almost one third of the children and adolescents consumed soft drink -on the previous weekday. That is substantially higher than has been reported in other Australian studies. One study, from another Australian state (Queensland) found that between 11 and $19 \%$ of females and 12 to $28 \%$ of males had consumed soft drinks on the previous day, with a marked increase with age [20]. In contrast to the current study the Queensland sample did not include adolescents from age 16-18 years, where we found a high proportion of consumers. A more recent study, based on the 2007 Australian National Children's Nutrition and Physical Activity Survey (NCNPAS), reported proportions of sweet drink consumers more similar to ours, in the range 19 and 38\% among males and 17 and 29\% among females for children aged 4-16 years [21]. The 
proportion of consumers of soft drink in the present study is; however, considerably lower than in other countries with comparable data. A 2004-05 study in Texas found that (depending on age) between 50 and $60 \%$ of children and adolescents aged 9-17 years consumed soft drink the previous day [33] and a Mexican study from 2006 reported that $76 \%$ of participants (511 years) consumed soft drink on a daily basis [34]. While there are methodological differences between these studies it seems likely that there are substantial differences in consumption of soft drink both between populations within Australia and between Australia and other countries. In addition, the prevalence of children and adolescents consuming any type of sweet drink (including both soft drink, sugar-sweetened beverages and fruit juice) is substantially higher in the United States (US) than was observed in the present study, according to analysis by Wang and colleagues based on the National Health and Nutrition Examination Surveys (NHANES) 1999-2004 [35]. They found that 90\% of the participants (2-19 years) consumed any type of sweet drink the previous day [35] compared to $77 \%$ in the present study at time 1 and $71 \%$ at time 2 .

In the present study more children and adolescents consumed fruit juice/cordial than soft drink, which is consistent with results from studies in the state of New South Wales $[2,3]$. In Texas, the proportion of children and adolescents consuming fruit juice, fruit-flavoured drinks and soft drinks was similar across all three categories of beverages (47-62\%) [33]. The study based on the Australian NCNPAS reported that overall $37 \%$ of children and adolescents consumed fruit juice, 25\% consumed soft drink and $20 \%$ consumed cordial on the previous day [21].

In the present study more participants in the older age groups consumed soft drinks. A similar trend has been observed in Queensland [20], nationally in the NCNPAS $[21,22]$ and in the US [33]. In the present study there were no differences between the age groups in the proportion of children drinking fruit juice/cordial. It was observed that among the adolescents more males than females consumed any sweet drinks and also the volume of sweet drinks consumed was higher among males, consistent with previous findings from Australia [20-22], Mexico [34] and Texas, US [33].

\section{Longitudinal changes over time}

In the cross-sectional analysis there was a higher proportion of consumers of soft drink in the older age groups. It was therefore expected that the proportion of consumers would increase with age (over time) in the longitudinal analysis. However, in the longitudinal analysis there was a non-significant trend towards a lower percentage of children and adolescents drinking any type of sweet drinks and fruit juice/cordial and soft drinks separately after approximately two year follow-up, although this was only significant for some age groups.

\section{Cross-sectional changes over time}

In the analysis of secular changes in consumption from time 1 to time 2 a similar non-significant trend was seen. These findings indicate a stable or even decreasing percentage of Victorian children drinking any type of sweet drink. Even though no intervention was made in the comparison groups the inclusion of the children and adolescents in the studies may have lead to greater awareness on healthy eating in general and decreased intake of sweet drinks and/ or decreased reported intake of sweet drinks. Furthermore, in BAEW the data at time 1 were collected over a long time period including summer/autumn while data at time 2 were collected in winter/spring, which may have affected the results as well. A recent study from Queensland, however, reported similar results as found in the present study for soft drink and concluded that there was a reduction of soft drink consumption in 2008 compared to 2003 [36]. Preliminary analysis from NHANES in the US (2003-04 and 2005-06) also indicate a decrease in the average intake of soft drink and fruit juice among US children [37]. The Australian Beverage Industry has reported a decrease in sales of sugar-sweetened carbonated soft drinks and an increase in sales of non-sugar-sweetened carbonated soft drink and water between 1997 and 2006, and especially from 2002 [38] which supports the observed trends in the present data.

The results from the present study also indicate a lower volume of soft drink intake at time 2 among the children (4-12 years) compared to time 1, however, the question assessing soft drink intake in BAEW was slightly altered from time 1 to time 2 and this may have had some effect on the apparent changes in intake of soft drink in most of the age groups from BAEW. Based on the data presented by the Australian Beverage Industry reporting an increase in the sale of diet beverages and water among the adult population [38] it is possible that some children and adolescents also have changed the intake of regular (sugar-sweetened) soft drink to diet soft drink or packaged water. In addition, there were substantial changes over the study period in the regulation and operation of school canteen services in Victoria, which may have impacted on the availability of sweet drinks on school days $[39,40]$.

\section{Strengths}

The strengths of the study include the collection of data on both one day's intake (yesterday/ last school day) and intake last week or month. The correlation between the two measurements is moderate to high [41], which 
supports the use of the single day recall questions that are generally simpler for participants to answer. The longitudinal design provides the opportunity to study changes in beverage intake within the same group of children over time and the combination of two closely related studies enabled assessment of beverage consumption patterns across childhood and adolescence in a large sample. The two studies had very similar designs, and methodological differences between them were relatively minor. One exception to this was the dietary data being self-reported by adolescents (IYM) and parentreported for primary school children (BAEW); however, given the ages of the participants, these methods are most appropriate for obtaining accurate recall data. Furthermore, the use of comparison groups meant that only the background health promotion activities were operating in the populations.

\section{Limitations}

The limitations of the study include that the analyses were based on single 24-hour reported beverage consumption, either yesterday's intake or intake on the last school day, which may not reflect long term intake due to day-to-day variation in food and beverage consumption. Furthermore, the use of one day's intake as an indicator of sweet drink consumption may increase the risk of misclassification and thereby the probability of type II errors. Moreover, the reported beverage intake is potentially subject to the limitations inherent in most dietary assessment methods including recall bias [42], underreporting [43] and social desirability bias [44], which may be especially pronounced for snack and sugar intakes [42]. Additionally, parents may not be fully aware of what their child drinks during the day, especially when the child is away from home [42]. In both studies only intakes of selected foods and beverages were assessed which imposes a substantially lower burden on the respondents [43] and may result in higher participation rates, among the adolescents compared to a 24-hour recall; however it precludes analyses that consider total energy or other nutrient intakes.

Due to the geographic limitation of the study, the results may not be generalizable to all Australian children and adolescents. Also the large number of participants lost to follow-up and the over representation of families residing in low SES areas restrict the generalisability of the results of the study. Generally, children and adolescents lost to follow-up between time 1 and time 2 had a higher intake of both soft drink and fruit juice/ cordial (BAEW: soft drink $\mathrm{p}=0.004$, fruit juice/cordial $\mathrm{p}$ $=0.03$, IYM: soft drink $\mathrm{p}<0.0001$, fruit juice $/$ cordial $\mathrm{p}=$ $0.08)$ than those participating at both time points. No difference was observed in BMI between children who participated at both time 1 and time 2 and children who were lost to follow-up after time $1(\mathrm{p}=0.37)$, while the adolescents who were lost to follow-up in IYM tended to have higher BMI than adolescents who remained in the study $(\mathrm{p}=0.06)$.

Beverage intake was reported only for weekdays, which may not represent usual intake, since it has been demonstrated that children eat differently on weekenddays compared to school days [45] and have a higher intake of soft drinks, but not fruit juice/cordial in the weekends [46]. Thus, the intake of sweet drinks reported in the present study may be lower than the actual intake. Although other studies have found that the majority of sugar-sweetened beverages was consumed at home $[21,22]$ the children and adolescents reported a high intake of sweet drinks in the present study, and at least some of this was likely to be consumed in school. Moreover, the intake of fruit juice/cordial was assessed in a combined question and it was therefore not possible to get separate information on these two beverages. Furthermore, no information was obtained on intake of other beverages such as diet beverages, milk and water and we are therefore not able to determine whether the decreased intake of sweet drinks is associated with increased intake of other types of beverages.

A final limitation of the studies is that the questionnaires not have been formally validated in their current form. The questions were selected on the balance of validation evidence from current literature and the feasibility of measuring large number of children. Moreover, the majority of the questions was taken or adapted from previously validated and widely used surveys in Australia and New Zealand and pilot testing was performed with both questionnaires before their use in the program evaluations [27].

\section{Conclusion}

This study showed that a large proportion of children and adolescents consumed sweet drinks, and of those, a higher proportion reported consuming fruit juice/cordial compared to soft drinks. The proportion of participants who reported consuming sweet drinks overall, and fruit juice/cordial specifically remained stable across age groups while there were a greater proportion of soft drink consumers in the older age groups. Overall, the proportion of consumers and the consumption of sweet drinks were high in this population and remained relatively stable over time. Although this study showed some evidence of a decrease in the intake from 2003 to 2008, there is still a great deal of room for improvement in the beverage intake of this population of Australian children and adolescents.

\section{Abbreviations}

BAEW: Be Active Eat Well; IYM: It's Your Move!; CATI: computer assisted telephone interview; OPIC: Pacific Obesity Prevention in Communities; 
BMI: body mass index; BMI z-score: body mass index z-score; US: United States; NHANES: the National Health and Nutrition Examination Survey; NCNPAS: National Children's Nutrition and Physical Activity Survey; SES: socioeconomic status: SEIFA: Socioeconomic Index for Areas.

\section{Competing interests}

The authors have no conflicts of interest to declare.

\section{Author's contribution}

AdSS, PK, BS and LM and were involved in the design, conduct and/or analysis of the intervention study evaluations. MN, SA and BWJ conceived the idea for this manuscript. BWJ conducted the data analyses and drafted the manuscript with supervision from SA and MN. All authors reviewed drafts of the manuscript and approved the final paper as submitted. BWJ was supported by the TrygFoundation, Centre for Intervention Research in Health Promotion and Disease Prevention (previous: Centre for Applied Research in Health Promotion and Prevention), The Danish Heart Foundation (10-04-R79-A2844-22578), the "Familien Hede Nielsen" foundation and University of Southern Denmark.

AdSS is supported by an NHMRC Capacity Building Grant and the Jack Brockhoff Foundation.

\section{Acknowledgments}

The authors would like to thank the many people involved in IYM and BAEW including co-investigators, other staff and postgraduate students, partner organisations, and especially the schools, students, parents and communities. The funding for IYM was from the Victorian Department of Health, the National Health and Medical Research Council (in conjunction with the Health Research Council (New Zealand) and the Wellcome Trust (UK) as part of their innovative International Collaborative Research Grant Scheme), and AusAID. BAEW was funded by the Commonwealth Department of Health and Ageing, the Victorian Department of Human Services and the Victorian Health Promotion Foundation (VicHealth).

\section{Author details}

'Research Unit for Dietary Studies, Institute of Preventive Medicine, Copenhagen Capital Region, Copenhagen University Hospital, Frederiksberg, Denmark. ${ }^{2}$ Centre for Research in Childhood Health, Institute of Sports Science and Clinical Biomechanics, University of Southern Denmark, Odense, Denmark. ${ }^{3}$ Centre for Intervention Research in Health Promotion and Disease Prevention (previous: Centre for Applied Research in Health Promotion and Prevention), The National Institute of Public Health, University of Southern Denmark, Copenhagen K, Denmark. ${ }^{4}$ WHO Collaborating Centre for Obesity Prevention, Deakin University, Geelong, Australia. ${ }^{5}$ Department of Public Health, University of Oxford, Oxford, United Kingdom. ${ }^{6}$ Melbourne School of Population Health, University of Melbourne, Melbourne, Australia. ${ }^{7}$ School of Psychology, Deakin University, Geelong, Australia.

\section{Received: 12 March 2012 Accepted: 30 August 2012}

Published: 12 September 2012

\section{References}

1. Commonwealth Scientific Industrial Research Organisation (CSIRO): Preventive health national research flagship, the University of South Australia. Canberra: 2007 Australian National Children's Nutrition and Physical Activity Survey - Main Findings: 2008. ACT.

2. Centre for Epidemiology and Research: 2005-2006 Report on child health from the New South Wales population health survey. Sydney: NSW Department of Health; 2008.

3. Hardy LL: NSW schools physical activity and nutrition survey (SPANS) 2010. Executive Summary; 2010.

4. Olsen NJ, Heitmann BL: Intake of calorically sweetened beverages and obesity. Obes Rev 2009, 10:68-75.

5. DiMeglio DP, Mattes RD: Liquid versus solid carbohydrate: effects on food intake and body weight. Int J Obes Relat Metab Disord 2000, 24:794-800.

6. Libuda L, Kersting M: Soft drinks and body weight development in childhood: is there a relationship? Curr Opin Clin Nutr Metab Care 2009, 12:596-600

7. Berkey CS, Rockett HR, Field AE, Gillman MW, Colditz GA: Sugar-added beverages and adolescent weight change. Obes Res 2004, 12:778-788.
8. Fiorito LM, Marini M, Francis LA, Smiciklas-Wright H, Birch LL: Beverage intake of girls at age $5 y$ predicts adiposity and weight status in childhood and adolescence. Am J Clin Nutr 2009, 90:935-942.

9. Ludwig DS, Peterson KE, Gortmaker SL: Relation between consumption of sugar-sweetened drinks and childhood obesity: a prospective, observational analysis. Lancet 2001, 357:505-508.

10. Phillips SM, Bandini LG, Naumova EN, Cyr H, Colclough S, Dietz WH, Must A: Energy-dense snack food intake in adolescence: longitudinal relationship to weight and fatness. Obes Res 2004, 12:461-472.

11. Striegel-Moore RH, Thompson D, Affenito SG, Franko DL, Obarzanek E, Barton BA, Schreiber GB, Daniels SR, Schmidt M, Crawford PB: Correlates of beverage intake in adolescent girls: the national heart, lung, and blood institute growth and health study. J Pediatr 2006, 148:183-187.

12. Tam CS, Garnett SP, Cowell CT, Campbell K, Cabrera G, Baur LA: Soft drink consumption and excess weight gain in Australian school students: results from the Nepean study. Int J Obes (Lond) 2006, 30:1091-1093.

13. Vartanian LR, Schwartz MB, Brownell KD: Effects of soft drink consumption on nutrition and health: a systematic review and meta-analysis. Am J Public Health 2007, 97:667-675.

14. Blum JW, Jacobsen DJ, Donnelly JE: Beverage consumption patterns in elementary school aged children across a two-year period. J Am Coll Nutr 2005, 24:93-98.

15. Johnson L, Mander AP, Jones $L R$, Emmett PM, Jebb $S A$ : Is sugar-sweetened beverage consumption associated with increased fatness in children? Nutrition 2007, 23:557-563.

16. Mundt CA, Baxter-Jones ADG, Whiting SJ, Bailey DA, Faulkner RA, Mirwald R: Relationships of activity and sugar drink intake on Fat mass development in youths. Med Sci Sports Exerc 2006, 38:1245-1254.

17. Vanselow MS, Pereira MA, Neumark-Sztainer D, Raatz SK: Adolescent beverage habits and changes in weight over time: findings from Project EAT. Am J Clin Nutr 2009, 90:1489-1495.

18. Forshee RA, Anderson PA, Storey ML: Sugar-sweetened beverages and body mass index in children and adolescents: a meta-analysis. Am J Clin Nutr 2008, 87:1662-1671. Erratum in: Am J Clin Nutr 2009; 89:441-2.

19. Mattes RD, Shikany JM, Kaiser KA, Allison DB: Nutritively sweetened beverage consumption and body weight: a systematic review and metaanalysis of randomized experiments. Obes Rev 2011, 12:346-365.

20. Abbott RA, Macdonald D, Stubbs CO, Harper C, Davies PSW: Healthy kids queensland survey 2006 - full report. Brisbane: Queensland Health; 2008.

21. Clifton $P$, Chan L, Moss C, Miller M, Cobiac L: Beverage intake and obesity in Australian children. Nutr Metab (Lond) 2011, 8:87.

22. Hafekost K, Mitrou F, Lawrence D, Zubrick S: Sugar sweetened beverage consumption by Australian children: Implications for public health strategy. BMC Public Health 2011, 11:950.

23. Bell AC, Simmons A, Sanigorski AM, Kremer PJ, Swinburn B: Preventing childhood obesity: the sentinel site for obesity prevention in Victoria, Australia. Health Promot Int 2008, 23:328-336.

24. Sanigorski AM, Bell AC, Kremer PJ, Cuttler R, Swinburn B: Reducing unhealthy weight gain in children through community capacity-building results of a quasi-experimental intervention program, Be active Eat well. Int J Obes (Lond) 2008, 32:1060-1067.

25. Sanigorski AM, Bell AC, Swinburn B: Association of key foods and beverages with obesity in Australian schoolchildren. Public Health Nutr 2007, 10:152-157.

26. Swinburn B, Pryor J, McCabe M, Carter R, de Courten M, Schaaf D, Scragg R: The Pacific OPIC Project (Obesity Prevention in Communities) objectives and designs. Pac Health Dialog 2007, 14:139-146.

27. Mathews L, Kremer PJ, Sanigorski A, Nichols M, Moodie M, Swinburn B: Methods and Tools. Victoria: 2008

28. Pink B: Information paper: an introduction to socio-economic indexes for areas (SEIFA), 2006. Belconnen: ACT; 2008

29. Davies P, Roodvelt R, Marks G: Standard methods for the collection and collation of anthropometric data in children. Brisbane: Australian Food and Nutrition Monitoring Unit UQ; 2001

30. WHO Multicentre Growth Reference Study Group: WHO child growth standards: length/height-for-age, weight-for-age, weight-for-length, weight-forheight and body mass index-for-age. Methods and development. Geneva: World Health Organization; 2006.

31. de Onis M, Onyango AW, Borghi E, Siyam A, Nishida C, Siekmann J: Development of a WHO growth reference for school-aged children and adolescents. Bull World Health Organ 2007, 85:660-667. 
32. de Onis $M$, Lobstein $\mathrm{T}$ : Defining obesity risk status in the general childhood population: Which cut-offs should we use? Int I Pediatr Obes 2010, 5:458-460.

33. Evans AE, Springer AE, Evans MH, Ranjit N, Hoelscher DM: A descriptive study of beverage consumption among an ethnically diverse sample of public school students in Texas. J Am Coll Nutr 2010, 29:387-396.

34. Barquera S, Campirano F, Bonvecchio A, Hernandez-Barrera L, Rivera JA, Popkin BM: Caloric beverage consumption patterns in Mexican children. Nutr J 2010, 9:47.

35. Wang YC, Bleich SN, Gortmaker SL: Increasing caloric contribution from sugar-sweetened beverages and 100\% fruit juices among US children and adolescents, 1988-2004. Pediatrics 2008, 121:e1604-e1614.

36. Slater PJ, Gkolia PP, Johnson HL, Thomas AR: Patterns of soft drink consumption and primary tooth extractions in Queensland children. Aust Dent J 2010, 55:430-435.

37. Storey LS, Anderson PA: Beverage consumption patterns in the US population [abstract]. FASEB J 2009, 229:4

38. Levy $G$, Tapsell $L$ : Shifts in purchasing patterns of non-alcoholic waterbased beverages in Australia, 1997-2006. Nutr Diet 2007, 64:268-279.

39. Australian Government Department of Health and Ageing: National Healthy School Canteens, Guidelines for healthy foods and drinks supplied in school canteens. 2010.

40. de Silva-Sanigorski A, Breheny T, Jones L, Lacy K, Kremer PJ, Carpenter L, Bolton K, Prosser L, Gibbs L, Waters E, et al: Government food service policies and guidelines do not create healthy school canteens. Aust N Z J Public Health 2011, 35:117-121.

41. Andersen LF: Kriterier ved validering av en metode for kostholdsundersøkelser-Når er validiteten til en metode tilfredsstillende? Norweigan (Criteria for the validation of dietary assessment methods. When is the validity satisfactory?). Nor J Epidemiology 2000, 10:17-24.

42. Livingstone MB, Robson PJ, Wallace JM: Issues in dietary intake assessment of children and adolescents. Br J Nutr 2004, 92(Suppl 2):S213-S222.

43. Magarey A, Watson J, Golley RK, Burrows T, Sutherland R, McNaughton SA, Denney-Wilson E, Campbell K, Collins C: Assessing dietary intake in children and adolescents: Considerations and recommendations for obesity research. Int J Pediatr Obes 2010, 6:2-11.

44. Livingstone $\mathrm{MB}$, Robson PJ: Measurement of dietary intake in children. Proc Nutr Soc 2000, 59:279-293.

45. McLennan W, Podger A: National Nutritional Survey. Nutrient intakes and physical measurements Australia. 1995. 1998.

46. Rockell JE, Parnell WR, Wilson NC, Skidmore PM, Regan A: Nutrients and foods consumed by New Zealand children on schooldays and nonschooldays. Public Health Nutr 2011, 14:203-208.

doi:10.1186/1471-2458-12-771

Cite this article as: Jensen et al:: Consumption patterns of sweet drinks in a population of Australian children and adolescents (2003-2008). BMC Public Health 2012 12:771.

\section{Submit your next manuscript to BioMed Central and take full advantage of:}

- Convenient online submission

- Thorough peer review

- No space constraints or color figure charges

- Immediate publication on acceptance

- Inclusion in PubMed, CAS, Scopus and Google Scholar

- Research which is freely available for redistribution

Submit your manuscript at www.biomedcentral.com/submit
( BioMed Central 